\title{
Literacy Programs for Incarcerated Youth in the United States
}

\author{
Diana Brace
}

\begin{abstract}
Incarcerated youth in the United States face many barriers to literacy learning. This paper collects and analyzes research on literacy programs in juvenile correctional facilities. The review of literature reveals a troubled institution lacking resources and clear solutions. Few articles deeply consider students' cultures, literacy identities, and voices. This discovery suggests that new approaches to research of incarcerated youth's literacy learning are needed. The paper calls for research that investigates and observes how literacy identities of incarcerated youth can be utilized to increase literacy learning both within and outside the correctional facility. The author further suggests that this goal could best be achieved by considering the theoretical frameworks of Bakhtin, Freire, and Peck, Flower, and Higgins.
\end{abstract}

\section{Introduction}

Incarcerated youth in the United States face many barriers to literacy learning. Yet research shows that participating in educational programs during incarceration reduces recidivism rates (Rozalski, Deignan, \& Engel, 2008). This literature review seeks to investigate the state of literacy education within juvenile educational facilities. While this review focuses on juvenile justice facilities in the United States, it could inform those working and researching in other educational settings where a diverse and marginalized population is not receiving adequate literacy instruction. These settings include adult correctional facilities and struggling urban and rural classrooms throughout the United States. The main research questions for this review of literature were broad: What do literacy programs in juvenile justice facilities look like? What kinds of instruction are effective? Why or why not? And how do cultural and institutional issues affect literacy learning in juvenile correctional facilities?

\section{Theoretical Frameworks}

The paper's perspective on literacy is informed by several theories, including Bakhtin (1994), Freire (2001), and Peck, Flower, and Higgins' (2001) “community literacy." These theories all promote critical literacy, and Freire (2001) and Peck et al. (2001) explicitly link learning literacy with creating social change.

Freire believes literacy is a critical tool of liberation for the oppressed to gain agency. Freire (2001) states: "[T]o acquire literacy is more than to psychologically 
and mechanically dominate reading and writing techniques. It is to dominate these techniques in terms of consciousness; to understand what one reads and to write what one understands; it is to communicate graphically" (p. 622). His overall philosophy, seeing literacy as a tool for liberation, condemns rote learning and teacher-centered classrooms. It encourages a culture of inquiry and critical thinking that asserts "an attitude of creation and re-creation, a self-transformation producing a stance of intervention in one's context" (p. 622). Freire (2001) wants students to "achieve critical consciousness so that they can teach themselves to read and write" (p. 627). His insistence on student agency in literacy learning is important in that it shifts power from the teacher to the student, calling for educators to be "partners of the students" (Freire, 2010, p. 75).

Peck et al. (2001) bring to light another crucial aspect in forging social change through literacy learning: forming new discourses through social practices. They refer to this "search for an alternative discourse" as "community literacy" (p. 575). The concept is grounded in problem-based learning, meaning students use literacy to solve a problem that affects them and their community. Under this view, students meet with other stakeholders in the community-some of whom are in direct conflict with the students' views-in order to resolve an issue they find problematic. By asking students to confront discourses that directly oppose their own, students are forced to "go beyond mere conversation to the delicate exploration of difference and conflict and toward the construction of a negotiated meaning" (p. 578). These conversations can result in "hybrid texts and discourses" (p. 580), meaning that the two discourses clash and recombine by the power of the conversation participants, creating a new discourse. Thus, the students' voices are legitimized, and they are active in constructing the change that they are seeking. Subsequently, when the students create a "hybrid text" by publishing, as exemplified in Peck et al., a newsletter that contained practical action steps alongside raps and commentary, they perpetuate the conversation into a different time and place, hopefully leading to further understanding and resolution. It also can further legitimize the shared discourse and maintain a respectful relationship between students and administration that was not there before the "hybrid discourse" emerged. This will hopefully lead to continued work toward goals bridging once hostile communication gaps within a community.

Students' conversations with community stakeholders in the research of Peck et al. (2001) demonstrate a strong resemblance to Bakhtin's theory of heteroglossia. Through conflict between the "outer forces and inner voices" (Peck et al., p. 581), or as Bakhtin would describe it, the struggle between the centripetal (dominant discourse) and centrifugal (stratifying, personal discourses) forces, discourse participants can "reveal ever newer ways to mean" (Bakhtin, 1994, p. 79). Just as community literacy guides students toward critical literacy by prompting them to consider their audience and the context of their audience's response, so does Bakhtin (1994) describe the dialogic between the speaker and listener: "[The speaker's] orientation toward the listener is an orientation toward a specific conceptual horizon, toward the specific world of the listener" (p. 76). This is a perspective grounded in the generative nature of social interaction. Peck et al. 
(2001) use this perspective to promote the creation of new discourses that can work toward social change within communities.

\section{Findings in the Literature}

A thorough search of scholarly online journals produced few results directly examining the effectiveness of literacy programs within juvenile correctional facilities. Several articles found echoed the fact that there is a dearth of research specifically addressing literacy instruction in juvenile correctional facilities (Foley, 2001; Krezmien \& Mulcahy, 2008; Mulcahy, Krezmien, Leone, Houchins, \& Baltodano, 2008; Rogers-Adkinson, Melloy, Stuart, Fletcher, \& Rinaldi, 2008). The majority of articles found were literature reviews or descriptive of research and data. Most of the literature also cited a 1997 study from The Center on Crime, Communities, and Culture, which claimed that helping students gain educational skills is one of the greatest ways to prevent future recidivism (Drakeford, 2002; Leone, Krezmien, Mason, \& Meisel, 2005; Malmgren \& Leone, 2000; Morrison \& Epps, 2002).

Findings from the literature are best categorized by instructional and systemic factors affecting literacy instruction. Throughout the literature instructional methods, materials, and the instructors using them are discussed. Further described are the student populations within United States juvenile correctional facilities. Systemic factors touched upon include structural culture and policy.

\section{Instruction}

Methods \& Materials. Most articles agree that a focus on remediation and drill and practice techniques are outdated and ineffective for the majority of students within juvenile correctional facilities. Foley (2001), Morrison \& Epps (2002), and RogersAdkinson et al. (2008) all noted an emphasis on tutoring and direct instruction. One study (Malmgren \& Leone, 2000) used a range of instructional techniques and materials (these are described in further detail below). Several other articles suggested implementing a variety of practices (Collier \& Thomas, 2001; Morrison \& Epps, 2002; Rogers-Adkinson et al., 2008). Both Collier and Thomas (2001) and Morrison and Epps (2002) focus on engaging in culturally relevant texts and literacy practices with incarcerated students. Rogers-Adkinson et al. (2008) describe several "key components of reading intervention" that include offering texts that are "culturally sensitive, meaningful to youth, highly engaging, and inclusive and respectful” (p. 207). This article also mentions the successful impact of Collaborative Strategic Reading (CSR) on comprehension for students with reading disabilities, second language learners, and struggling readers (p. 206). CSR groups students by literacy levels to help each other employ meta-cognitive reading strategies.

Additionally, the Corrective Reading series is used frequently in studies validating the effectiveness of direct instruction with incarcerated teenagers (Drakeford, 2002; Malmgren \& Leone, 2000; Mulcahy et al., 2008) This program is a commercial, scripted instructional reading model published by McGraw-Hill and 
developed by Science Research Associates (Rogers-Atkinson et al., 2008). It contains two strands, decoding and comprehension, and provides materials for four reading levels (Corrective Reading website). Drakeford (2002) used Corrective Reading and achieved positive results in his eight week study of reading students in a correctional facility in Maryland that houses male and females aged 12 through 21. He utilized a single-subject multiple baseline study using the program and a sample size of six (two groups of three) students who were all African American males with low reading scores and a mean age of 17 . Students gained in oral reading fluency scores, grade level placements, and claimed an improved attitude toward reading. Malmgren and Leone (2000) used the Corrective Reading curriculum in combination with whole language approaches and teacher read-alouds. The researchers designed a six-week study using pre-tests and post-tests for teenagers in a juvenile detention facility. The study found significant gains in reading rate, accuracy, and rate and accuracy combined, though no significant gains were found in reading comprehension. The researchers also cited a loss of almost $50 \%$ of their original sample size, ending with 45 African-American male participants, averaging 17 years of age. Mulcahy and her colleagues (2008) stated in their study that "[t]he instructors had difficulty maintaining participant involvement with the Corrective Reading series," citing "student disdain" for the Corrective Reading portions of the program (p.249). This led Mulcahy et al. (2008) to find and develop their own instructional materials that included age-appropriate texts for students reading at a lower level and activity sheets to accompany Read Naturally passages (p.243). They further suggest that researchers continue to "develop curriculum materials and assessments appropriate for this population of youth" (p.244).

\section{Students \& Instructors}

Diversity of student population. The achievement gap found in public schools between minorities and Caucasian students is similarly evident in correctional facility education programs (Rogers-Adkinson et al., 2008). There is a pronounced over-representation of minorities, particularly African-American males, within juvenile correctional facilities (Leone et al., 2005; Morrison \& Epps, 2002). Leone et al. (2005) provided some staggering statistics:

The long-standing pattern of disproportionate arrest and incarceration of minority juveniles is a disturbing national problem (Poe-Yamagata \& Jones, 2000). Over-representation is especially pronounced for African-American youth who constitute $14 \%$ of the overall population ages 10 to 17 but $40 \%$ of all incarcerated juveniles nationally and are 5 times more likely to be incarcerated than Caucasian youth (Sickmund, 2004). Latino and Native American youth are 2.5 times more likely to be incarcerated than Caucasian youth (Poe-Yamagata \& Jones, 2000). (pp. 91-92)

Leone et al. (2005) follow these statistics with a call for more "culturally relevant curriculum" (p. 92), though they never explicitly state what such a curriculum would look like. 
There is also an over-representation of students with emotional disturbance (Malmgren \& Leone, 2000), as well as behavioral and learning disabilities (Foley, 2001; Krezmien et al., 2008; Morrison \& Epps, 2002; Rogers-Adkinson et al., 2008). Some states have reported that between $60 \%$ to $70 \%$ of incarcerated youth receive special education services (Leone et al., 2005, p. 91).

Collier and Thomas (2001) address the English language learner population within US correctional facilities, advising educators to transplant research-based English as a second language instructional practices into the correctional facility setting. They advocate bilingual education, teaching the second language through content, and teaching literacy in the student's primary language. They further address emotional and sociocultural needs of learners.

In their 2006 literature review, Harris, Baltodano, Artiles, and Rutherford detail the lack of research integrating culture into instruction, as well as the "absence of cultural considerations when teaching and evaluating incarcerated youth" (p. 761). Like Collier and Thomas (2001), Harris et al. (2006) urge those educating the diverse population of incarcerated youth to recognize "youth's sociocultural contexts of literacy" (p. 753)-an important factor when providing authentic and meaningful literacy practices to these students that "may not perceive school literacy to be a valuable skill" (p. 753).

Here may be an appropriate time to expand on the disconnect between "school literacy" - one often reiterated in juvenile correctional facility classrooms as noted in the literature review of Harris and her colleagues (2006)-and the literacies of the ethnically diverse population of students most often found in these facilities. The "school-to-prison-pipeline" is a term used to describe why there is the previously described over-representation of minorities in juvenile correctional facilities and prisons. Winn and Behizadeh (2011) provide a concise summary of the school to prison pipeline literature. They delve into literacy as a civil right, and how this right has been denied to many students in poor, urban, predominantly minority populated areas. The authors note that a "focus on basic skills, remediation, and overzealous test preparation" are the problems faced by classrooms populated by students of color (p. 150). They go on to chide the irony of No Child Left Behindmeant to close the achievement gap, when in actuality, NCLB is only widening the gap by implementing a decreasingly rigorous curriculum meant only to prepare students for high-stakes testing, not critical thinking (p. 152). Such curriculum has been criticized for its "subordination of knowledge and identity historically experienced by marginalized groups" (Lipman, 2008 as cited in Winn \& Behizadeh, 2011, p. 152). The curriculum described brings to mind Freire's notion of "banking education", in which the oppressed are merely fed knowledge by their teacher rather than engaged in critical and empowered thinking. It is this sort of "banking"type schooling that the authors' claim promotes high dropout rates that can lead to incarceration-i.e., the school-to-prison pipeline. As mentioned above, research has found that this type of remediation and drill and skill curriculum is prevalent in juvenile correctional facility classrooms in the United States. 
Instructors. Many articles noted a scarcity of highly qualified or certified instructors in juvenile correctional facilities. Instructors may lack knowledge of reading instruction best practices. Several articles reported staff with low selfefficacy, low morale, and a reluctance to cooperate with researchers (Drakeford, 2002; Krezmien \& Mulcahy, 2008; Malmgren \& Leone, 2000; Mulcahy et al., 2008. More on correctional facility culture below.) Leone et al. (2005) also found that instructors can feel isolated from professional development opportunities and the educational community in general (p. 94). At the same time, it may be difficult for instructors to form relationships with students due to the correctional environment (Rogers-Adkinson et al., 2008; Taymans \& Corley, 2001). This disconnect in turn affects students, because Rogers-Adkinson et al. (2008) note that students within correctional facilities may value and consider their relationships with educators important to their future success. Suggestions from Taymans and Corley (2001) for improved relationships between instructional and correctional staff at adult facilities are mentioned below in the broader context of correctional culture and systemic issues.

\section{Correctional Culture \& Systemic Issues}

Although the purpose of much of the literature was to discuss incarcerated youth's academic struggles, many studies briefly touched on contextual factors that affect how those strategies are successful or not successful in the classroom. According to the research, collaboration between all stakeholders, from sheriff to correctional officer, from social worker to teacher, is imperative in providing as much consistency as possible to enable student learning (Drakeford, 2002; Leone et al., 2005; Taymans \& Corley, 2001). Several articles mentioned disagreements between correctional officers and educators, as well as correctional officers and researchers (Drakeford, 2002; Leone et al., 2005; Mulcahy et al., 2008). Leone et al. (2005) state: "[C]orrections and education personnel working within the same juvenile facility may have conflicting perspectives about whether punishment and control or rehabilitation and treatment should be the governing principles for youth incarceration" (p. 93). Drakeford (2002) explicitly addresses the need to change "institutional culture" (p. 143) in order to incentivize educational improvement. One way this could be done is through increased communication between staff and students which in turn can increase staff's awareness of the incarcerated youth's situations, as further described below by Taymans and Corley (2001).

Due to the high percentage of students with learning disabilities, Taymans and Corley (2001) also note the need for all correctional facility personnel to have an awareness and "understanding of learning disabilities, their manifestations, and their consequences" (p. 74). Through this awareness, the correctional culture may become more receptive to issues faced by inmates with learning disabilities, and work to provide educational opportunities to these inmates. While the authors discuss learning disabilities in particular, one could see how educating correctional officers and staff about other aspects of the youth's lives and cultures could prove beneficial to both the youth and those working in the correctional facilities. 
On a broader structural level, Taymans and Corley (2001) sought to provide suggestions for systemic reform within educational programs for correctional facilities. Their article solely discussed US adult correctional facilities, reiterating the need for further exploration into the culture of juvenile correctional facilities in the United States. They focused on collaboration, setting shared goals, gathering resources and funds, providing adequate professional development to improve instruction, and assessing whether these reforms have achieved better learning for inmates with learning disabilities.

Overall, Mulcahy et al. (2008) highlight the role of law and policy in the problem of educating incarcerated youth: "[T]he absence of policy guidelines for education and special education services in juvenile corrections highlights a situation in which a marginalized group of children may be denied the right to an education that is afforded to their peers in public schools" (p. 240).

\section{Research Analysis \& Implications \\ Lack of Cultural and Critical Perspectives on Literacy}

While many articles acknowledge the diversity and common over-representation of minorities within juvenile correctional facilities, few provide substantial practical suggestions. This may be due in part to the quantitative design of the research, as well as the focus on special education instruction. The focus appears to be on the methods of instruction taught in the classroom, and not the knowledge the students bring to the classroom. This apparent disregard in the literature of researching-or clearly defining-culturally responsive instruction is problematic.

While Drakeford (2002) and Malmgren and Leone (2000) had some success with certain direct instruction materials, there is little other evidence to suggest direct instruction will consistently work within a correctional facility. Does direct instruction work on its own? (Malmgren and Leone (2000) used whole language approaches and teacher read-alouds along with the Corrective Reading direct instruction materials.) What other instructional methods can supplement direct instruction in order to provide students with greater access to the texts?

Collier and Thomas (2001) engage the reader in a perspective that values students' voices, knowledge, and cultural backgrounds. Yet, they do not fully integrate the implications of their theories and practice for English language learners so they can be applied to students within the correctional setting. Instead, the authors advocate for the transference of best practices for ESL students into correctional facilities. This transfer is appropriate to an extent, but it fails to consider a multitude of other factors that exist within a correctional facility that may not be addressed through what are considered best practices in a different setting.

How can research connect the instructional methods research found in several studies with the more sociocultural and anthropological perspective Collier and Thomas (2001) took? As mentioned above, Rogers-Adkinson et al. (2008) offer ideas for differentiated instruction with cultural background and student engagement in mind. These ideas-especially providing students with a variety of 
texts they may connect to and opportunities for collaborative group learning-are a great start. But none of these proposed strategies have been fully researched within a correctional facility. How effective would they be?

While Drakeford (2002) and Malmgren and Leone (2000) focus on special education instruction in a treatment study design, they rightfully seek to address the need for intensive, time-sensitive reading instruction for adjudicated youth (youth being detained until formal sentencing). This can be a time when little educational progress is made due to the uncertainty of the youths' situations. Thus, research on intense intervention that can be implemented when possible during this flux period is needed.

\section{Problems in Correctional Culture and Systemic Issues}

Throughout the literature on correctional education, there are cries for collaboration and a shared goal of putting rehabilitation first. If correctional educators are in conflict with facility administration or officers, student learning can be pushed aside. Things are further complicated when researchers are brought into the facility. How do you balance the focused interest of researchers attempting to improve literacy practices, with the broader interests of the correctional personnel on site every day?

Underlying many of these systemic problems-philosophical conflicts between staff and educators, a lack of qualified educators, as well as inconsistent student attendance and high student turnover rates-are policies and laws over which the educator has little influence. While more difficult to change, it is important to acknowledge and understand the effect that state and federal policy and law have on how incarcerated youth are treated and educated. Even though inmates under 21 are required by law under the Elementary and Secondary Education Act to be offered educational services within correctional facilities (Foley, 2001), students are not receiving high quality educational services. This has resulted in numerous lawsuits and investigations at the state and local levels to bring juvenile correctional facility educational programs in sync with federal law (Mulcahy et al., 2008). How can these broader institutional issues be addressed in research? How can these issues be addressed within the literacy classroom where we find those most affected by these policies and laws - the inmates?

Taymans and Corley (2001) rightfully address the importance of obtaining and maintaining sources of funding and materials by corralling stakeholders and community organizations to, in a way, "sponsor" literacy. Taking these "sponsors of literacy" (Brandt, 2001) into account is worthwhile when researching the cultural and systemic-or the more global-details of literacy learning within a juvenile correctional facility. What materials are in the classroom? Who is providing these materials? What resources are missing and why? How does the lack of resources affect incarcerated youth's motivation to learn? 


\section{Issues in Research Methodology}

As mentioned above, the majority of research in this area is descriptive data analysis, with two quantitative, empirical studies using a treatment research design. The difficulty in administering valid quantitative studies is admitted within a few of articles themselves. Mulcahy et al. (2008) stated that the level of quantitative research now valued "may not be possible in all juvenile corrections facilities because of the highly volatile nature of the settings" (p. 250). Krezmien and Mulcahy (2008) noted "the absence of an emphasis on intensive empirically validated reading programs in juvenile corrections settings contrasts with the current push from the No Child Left Behind Act of 2001 (2002) to implement systematic and scientifically based reading programs" (pp. 221-222). Yet perhaps because of this push, researchers continue to suggest further quantitative methods rather than mixed methods or qualitative research. Peck et al. (2001) call for mixed methods within community literacy that I believe applies well to the need to expand research options within juvenile correctional facility literacy programs: "But a robust community literacy must embrace multiple kinds of inquiry-from systematic analyses to personal reflections in which both community and university people develop an awareness of the practices they bring and the ways they might be adapted" (p. 586).

Mulcahy et al. (2008) discussed the challenges facing reading researchers wanting to design valid quantitative studies within juvenile correctional facilities. These challenges include: difficulties collaborating with administrators, decreasing sample size due to release dates, inadequate materials and instructional settings, as well as sporadic student schedules. The article also noted that reading researchers must yield to research from the special education field because of the lack of research within youth correctional facilities (p. 241).

Due to the difficulties that have arisen within these quantitative studies, perhaps researchers should consider different methods. Morrison and Epps (2002) supplemented their data analysis and instructional suggestions with case studies. Exploring incarcerated youths' literacy through ethnographic research would prove beneficial in understanding the literacies that they carry with them into the correctional education setting, and what literacies they will leave that setting with. By critically investigating and observing the literacies of incarcerated youth, we may better "make use of the students' linguistic and cultural knowledge to bridge to new knowledge" (Collier \& Thomas, 2001, p. 68).

Again, many researchers tout statistics and surveys to depict the dilapidated state of the United States' juvenile justice educational system. They detail the overrepresentation of minorities and students with disabilities. It should be noted that these are issues often faced in adult correctional facilities and disadvantaged urban and rural classrooms in the United States, as well. These are incredibly important to acknowledge, but it is time to move beyond reporting and time to start using what we know to look for new ways to attend to the problems entrenched in juvenile justice facilities. 


\section{Implications for the Correctional Classroom}

The students within correctional facilities have very little power. They are told where they go, what they do, and when. There is a crucial place for literacy learning within this environment that, while not overlooked, hasn't been considered to the extent it should. While incarcerated youth may not have the typical academic literacy skills valued by our society, they carry literacies into the facility. Through the proposed theories, they could be able to leave with additional literaciesconstructed from their own literacies.

Due to the diversity within a youth correctional facility, an instructional theory or framework must be one that can be applied to a heterogeneous group of students who have different cultures, languages, literacy abilities, and experiences. One must also note the unique educational environment found in correctional facilities-one of limited freedoms and resources for students. Adolescents are often suspicious of authority-imagine students who must deal with coercive adults nearly every day while incarcerated. With these challenges in mind, Bakhtin (1994), Freire (2001), and Peck et al. (2001) provide glimpses into applicable theoretical frameworks.

Bakhtin (1994) provides a basis for understanding that language is constantly evolving through conversations with others and with ourselves. His notion of heteroglossia also pertains to incarcerated youth as they struggle against a dominant discourse of which they are not a part. By making students aware of the dominant discourse in a way that highlights this struggle, rather than asking them to assimilate to the discourse, students may come away with new meaning.

Freire (2001) and Peck et al. (2001) describe a "process"-there is a visible framework for implementation. Freire's process and "community literacy" are structures that can be adapted and also work toward social change.

It would be interesting to see how Freire's (2001) process of teaching basic literacy through culturally relative generative words-words that come from the learners' culture and experiences from which literacy instruction can be built upon -would work within a correctional facility. Freire's process has been shown to work in an astonishingly short amount of time (p. 627). Freire wants students to "achieve critical consciousness so that they can teach themselves to read and write" (p. 627). This is imperative when considering that educators within juvenile correctional facilities often have students for only a brief period of time. There is an urgency to motivate and teach students how to teach themselves.

As mentioned above, students within correctional facilities have very little power. Whether or not their crimes warrant this loss of power is not the issuethey are there, and have the right to an education. With this context in mind, one can see how the framework of community literacy (Peck et al., 2001) could act as a mediation tool between student inmates, correctional officers, and facility administration. If an open, intercultural dialogue can be established between a literacy class of incarcerated youth and correctional officers, students can not only increase literacy skills in an authentic manner, but also work toward improving 
structural problems using that literacy. Critical thinking skills developed through the community literacy framework can be used outside of the classroom. Perhaps most importantly, the framework allows students to have agency in their learning, hopefully demonstrating to the incarcerated youth the power their voices have to challenge the dominant discourse, construct new meaning, and solve problems.

One can see how these theories express themselves in creating new studentled discourses with The Insight Project, part of a New York City Alternative to Incarceration Program that includes students who are involved in the criminal justice system (Vasudevan, Stageman, Jay, Rodriguez, Fernandez, \& Dattatreyan, 2010). Here students engage in storytelling, improvisation, and dramatic performances. As the improvisations turned to scripts and rehearsed lines, students began to critically view the characters they had created, considering multiple perspectives pushed by critical dialogue with their teacher. Thus, rehearsals "became spaces for the youth to re-imagine the script they would perform on stage, as well as spaces within which to rehearse and re-script their own life narratives" (p. 62). They create new discourses and identities through literacy practices. After performances, students engaged in talkbacks, where audience members would ask the students questions. The talkbacks provided another venue for generating new discourses, allowing students "to portray themselves outside of the stereotypes and familiar expectations of posturing that followed them across contexts" (p. 63). This harkens to Bakhtin's notion of pushing against the dominant discourse with unique literacies, as well as the generation of new meaning through the dialogic between speaker and listener.

They are also, in a sense, engaging in community literacy as they work with teachers and other stakeholders to create a new discourse in the form of a play for a community audience. In facing questions during talkbacks, the students may dialogue with those who may not agree with or understand their narrative. This pushes students to again create new discourses as they work to answer the audience's questions in a meaningful way. Furthermore, these talkbacks place the students in the role of teacher-consistent with Freire's theories of student agency-the audience learning from the Insight Project participants' experience. One participant of the program is provided further authority and agency over the discourse by being named a coauthor on the article.

In addition to providing open spaces for students to author themselves, the program takes the Freirian notion of generative themes mentioned above. Each script begins with the words created during student improvisation, thus plays are built upon the cultural knowledge and experiences of the students-not of the teachers.

As Vasudevan and her coauthors (2010) note, while "institutions of education and justice are often characterized as sites of oppression, there are hopeful and generative possibilities for imaginative education within the institutional walls" (p. 64). If students are provided the space to demonstrate agency and create new discourses they may leave incarceration with new literacies that can better solve problems and lead an effort toward social change. 


\section{Potential Problems}

Freire's (2001) focus on basic literacy is certainly applicable to the number of incarcerated youth who are illiterate. Has Freire's process been attempted within the United States? If so, has it been effective? Even though the particular process of using generative words to build literacy may not be applicable to adolescents in youth correctional centers, his notion of "appropriating the mechanism critically... to produce..."(p. 625) could be translated to certain genres of writing and speaking. Vasudevan et al.'s (2010) work shows how his theories could be applied to writing and speaking, and further thought and research should investigate the possibilities of The Insight's Project's approach with detained youth.

The community literacy approach also contains some limitations. We are unsure of the literacy levels of the participants involved, but from the writing examples, it is evident that the students are writing above the fourth grade level [what is considered the average level of reading for incarcerated youth (Drakeford, 2002; Foley, 2001; Malmgren \& Leone, 2000)]. While students do not necessarily need to be reading at grade level in order to think critically, if the community literacy framework were to be implemented, educators may need to supplement instruction in reading and writing for students struggling or with learning disabilities. The framework could provide the authentic motivation for struggling students to work toward improving their basic skills.

Bakhtin (1994), Freire (2001), and Peck et al. (2001) all battle with issues of power and dominance within speech genres, discourses, and literacy learning. These power struggles can be exacerbated in the emotional environment of a correctional facility. The reason why educators may be hesitant in initiating intercultural conversations that look critically at power in the classroom is aptly put by Peck et al. (2001): "The agenda of integrating cultural practices draws us into a value-laden tangle of decisions about power" (p. 574). Building enough trust between educator and students to navigate through this uncomfortable "tangle of decisions about power" within intercultural dialogue may be the greatest challenge to literacy educators in correctional facilities. The community literacy framework offers needed practical solutions, but without the initial push for intercultural dialogue from all stakeholders, the entire framework is inapplicable. How easily could this framework fall apart with a sudden shift in power or loss of trust? And what correctional facility would believe in an instructional plan that gave power to the inmates they are attempting to keep under control? This question returns us to the fundamental conflict in philosophies noted in Leone et al. (2005): "punishment and control or rehabilitation and treatment" (p. 93).

\section{Conclusion and Further Directions}

It is obvious from the research that more needs to be done to promote a passion for inquiry among incarcerated youth. Unfortunately, the institutional barriers are daunting, and the diversity of the population within these correctional facilities can make instructional planning more difficult. What is missing from most of this research is the promotion of agency in the learner, the need to "nourish the critical 
spirit" (Freire, 2001, p. 628), so that students may leave incarceration with a renewed sense of confidence in their voice and ability as a learner.

As we attempt to look closer to the local cultural context of each student, we also need to investigate the variety of external, global factors. Like the public school system, the correctional education system is diverse-not only in student population, but in facility offerings and conditions. They include youth and adult populations, state and federal facilities, cultures of rehabilitation and cultures of punishment. It's my hope that the theories and research in this literature review can potentially guide educators and researchers throughout the diverse criminal justice system, as well as lower-socioeconomic public school classrooms. Additionally, researchers should consider the dominant discourse that pushes against the call for improved literacy education for inmates. What are current public opinions of the juvenile justice system and how best to handle the issue? Is there any political will? While we've seen growing concern on the federal level from the Department of Education in regards to preventing high school dropout, does this translate to aid and research for incarcerated youth? Is the level of support real or rhetorical? The entanglement of correctional education with politics and law makes the search and implementation of solutions that much more difficult at the same time the need for solutions becomes more urgent.

\section{References}

Bakhtin, M. M. (1994). The dialogic imagination. (Trans. M. Holmquist \& C. Emerson.) In P. Morris (Ed.), The Bakhtin reader: Selected writings of Bakhtin, Medvedev, Voloshinov (pp. 74-80). London: Edward Arnold. (Original work published in 1935).

Brandt, D. (2001). Sponsors of literacy. In E. Cushman, E. R. Kintgen, B. M. Kroll \& M. Rose (Eds.), Literacy: A critical sourcebook (pp. 555-571). Boston: Bedford/ St. Martin's.

Collier, V. P., \& Thomas, W. P. (2001). Educating linguistically and culturally diverse students in correctional settings. Journal of Correctional Education, 52(2), 6873.

Corrective Reading. (n.d.). Retrieved from http://www.mcgrawhill.co.uk/sra/correctivereading.htm

Drakeford, W. (2002). The impact of an intensive program to increase the literacy skills of youth confined to juvenile corrections. Journal of Correctional Education, 53(4), 139-143.

Foley, R. M. (2001). Academic characteristics of incarcerated youth and correctional educational programs: A literature review. Journal of Emotional and Behavioral Disorders, 9(4), 248-259. 
Freire, P. (2001). The adult literacy process as cultural action for freedom and education and conscientização. In E. Cushman, E. R. Kintgen, B. M. Kroll \& M. Rose (Eds.), Literacy: A critical sourcebook (pp. 616-628). Boston: Bedford/St. Martin's.

Harris, P. J., Baltodano, H. M., Artiles, A. J., \& Rutherford, R. B. (2006). Integration of culture in reading studies for youth in corrections: A literature review. Education and Treatment of Children, 29(4), 749-778.

Krezmien, M. P., \& Mulcahy, C. A. (2008). Literacy and delinquency: Current status of reading interventions with detained and incarcerated youth. Reading \& Writing Quarterly, 24, 219-238.

Leone, P. E., Krezmien, M., Mason, L., \& Meisel, S. M. (2005). Organizing and delivering empirically based literacy instruction to incarcerated youth. Exceptionality, 13(2), 89-102.

Malmgren, K. W., \& Leone, P. E. (2000). Effects of a short-term auxiliary reading program on the reading skills of incarcerated youth. The Education and Treatment of Children, 23(3), 239-247.

Morrison, H. R., \& Epps, B. D. (2002). Warehousing or rehabilitation? Public schooling in the juvenile justice system. Journal of Negro Education, 71(3), 218-232.

Mulcahy, C. A., Krezmien, M. P., Leone, P. E., Houchins, D. E., \& Baltodano, H. (2008). Lessons learned: Barriers and solutions for conducting reading investigations in juvenile corrections settings. Reading \& Writing Quarterly, $24,239-252$.

Peck, W.C., Flower, L., \& Higgins, L. (2001). Community literacy. In E. Cushman, E. R. Kintgen, B.M. Kroll \& M. Rose (Eds.), Literacy: A critical sourcebook (pp. 572587). Boston: Bedford/St. Martin's.

Rogers-Adkinson, D., Melloy, K., Stuart, S., Fletcher, L., \& Rinaldi, C. (2008). Reading and written language competency of incarcerated youth. Reading \& Writing Quarterly, 24, 197-218.

Rozalski, M., Deignan, M., \& Engel, S. (2008). The world of juvenile justice according to the numbers. Reading \& Writing Quarterly, 24, 143-147.

Taymans, J. M. \& Corley, M. (2001). Enhancing services to inmates with learning disabilities: Systemic reform of prison literacy programs. Journal of Correctional Education, 52(2), 74-78.

Vasudevan, L., Stageman, D., Jay, J., Rodriguez, K., Fernandez, E., \& Dattatreyan, E. G. (2010). Authoring new narratives with youth at the intersection of the arts and justice. Perspectives on Urban Education, 7(1), 54-64.

Winn M. T., \& Behizadeh, N. (2011). The right to be literate: Literacy, education, and the school-to-prison pipeline. Review of Research in Education, 35, 147-173. 